\section{Transient right-to-left shunting through a patent foramen ovale secondary to unilateral diaphragmatic paralysis}

\author{
P J Cordero, P Morales, V Mora, \\ J Cebrian, J Vallterra, J Gudin, \\ E Benlloch, V Marco
}

\begin{abstract}
A 57 year old patient presented with unilateral diaphragmatic paralysis and severe hypoxaemia secondary to transient rightto-left interatrial shunting through a patent foramen ovale. The final diagnosis was made because of the initial detection of a shunt while the patient was breathing $100 \%$ oxygen.
\end{abstract}

(Thorax 1994;49:933-934)

Patent foramen ovale is the most common characteristic of the fetal circulation which may persist after the neonatal period. Although this anomaly has no clinical implications, it is a potential route of right-to-left shunt when the right atrial pressures are high. Only a few cases in which shunting occurred despite normal right atrial pressures have been described. ${ }^{12}$ The mechanisms that lead to this condition are not known. The occurrence of patent foramen ovale with right-to-left shunt should be suspected in all cases of unexplained dyspnoea with arterial oxygen desaturation in the absence of other cardiopulmonary disease.

\section{Case report}

A 57 year old male farm labourer was admitted to our hospital with a suspected paralysis of the right hemidiaphragm. His presenting symptom was progressive exertional dyspnoea over the previous month and intolerance of the decubitus position. Chest radiography was normal. No improvement followed over the next two weeks and he presented to us with dyspnoea on minimal effort.

Physical examination showed decreased ventilation at the right base, tachypnoea (respiratory rate 26 breaths/minute) and tachycardia (heart rate 120 beats/minute). The haemoglobin and a biochemical screen were normal. Arterial blood gas tensions when breathing room air were $\mathrm{PaO}_{2} 4.93 \mathrm{kPa}, \mathrm{PaCO}_{2}$ $4.26 \mathrm{kPa}, \mathrm{HCO}_{3}{ }^{-} 24 \mathrm{mEq} / \mathrm{l}$, and $\mathrm{pH} 7 \cdot 48$. A chest radiograph showed elevation of the right hemidiaphragm with paradoxical movement during inspiration which increased with the sniff manoeuvre. An electrocardiogram revealed sinus tachycardia with anterior hemiblock and incomplete right bundle branch block. Abdominal and thoracic ultrasonography and computed tomographic scanning excluded subphrenic and hepatic pathology. Pulmonary function tests revealed a mild restrictive ventilatory defect (vital capacity 2.761 ( $67 \%$ predicted), $\mathrm{FEV}_{1} / \mathrm{FVC} 77 \%$, total lung capacity $4.561(79 \%))$. The single breath transfer factor for carbon monoxide (TLCO) was normal (109\%). A right-to-left shunt was detected while the patient breathed $100 \%$ oxygen in the sitting position $\left(\mathrm{Po}_{2} 7.73 \mathrm{kPa}, \mathrm{PCO}_{2}\right.$ $4.8 \mathrm{kPa}$ ). Maximal static inspiratory mouth pressure (PImax) was reduced $\left(-72 \mathrm{~cm} \mathrm{H}_{2} \mathrm{O}\right)$ while expiratory mouth pressure (PEmax) was normal $\left(165 \mathrm{~cm} \mathrm{H}_{2} \mathrm{O}\right)$. Electromyographic studies of the right hemidiaphragm with stimulation of the phrenic nerve suggested the occurrence of a neurapraxia. A ventilationperfusion scan showed defects which were consistent with the radiographic findings. Pulmonary arteriography was normal. Transoesophageal echocardiography (figure) showed a patent foramen ovale with a right-to-left shunt from the inferior vena cava towards the foramen ovale in the interatrial septum, later confirmed by arterial angiography. Cardiac catheterisation showed normal pressures and resistance in the pulmonary artery.

Another chest radiograph taken six weeks later, while the patient was being assessed for surgical correction, showed the right diaphragmatic paralysis to have resolved. Arterial blood gas tensions when breathing room air were $\mathrm{PO}_{2} 10.4 \mathrm{kPa}, \mathrm{PCO}_{2} 4.2 \mathrm{kPa}$ and, after breathing $100 \%$ oxygen, $\mathrm{Po}_{2} 75.7 \mathrm{kPa}, \mathrm{PCO}_{2}$ $5.8 \mathrm{kPa}$ (Qs/QT of $6 \%$ with an assumed arteriovenous oxygen content difference of $5 \mathrm{ml} \%$ ).

Transoesophageal echocardiography confirmed the disappearance of the right-to-left shunt.

\section{Discussion}

Patent foramen ovale is a common finding among healthy people, its incidence ranging from $20 \%$ to $35 \%$ in necropsy series. ${ }^{3}$ It is often overlooked because no abnormalities are found on physical, electrocardiographic, or radiological examination; nevertheless, the importance of patent foramen ovale is that any condition causing a higher pressure in the right atrium than the left may lead to a right-to-left shunt with systemic arterial desaturation and possibly paradoxical emboli. ${ }^{4}$ This may occur during crying in the neonate, ${ }^{5}$ the Valsalva manoeuvre, ${ }^{6}$ during positive end expiratory

Returned to June 1993

11 October 1993

Revised version received

8 November 1993

22 November 1993 

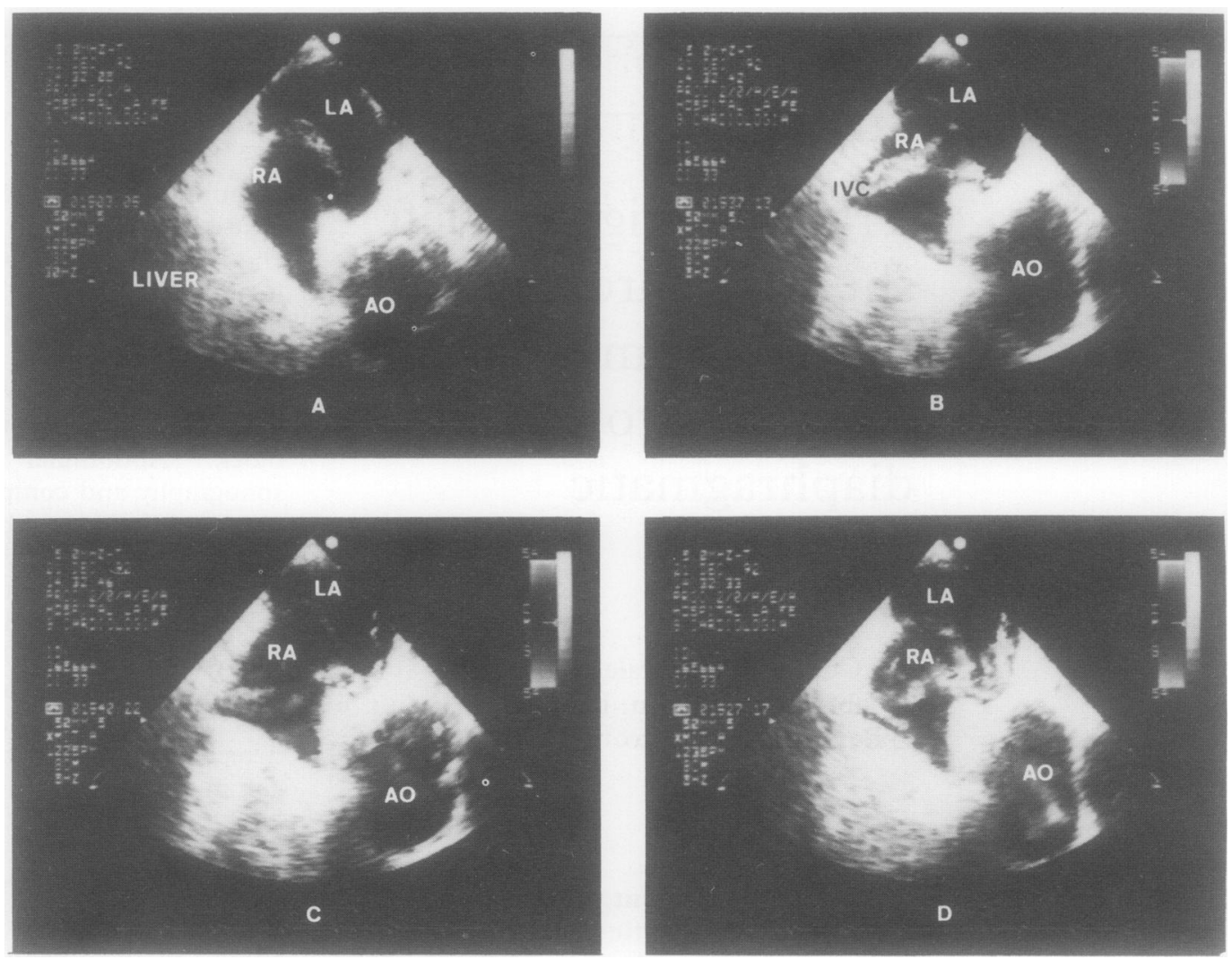

(A) Transoesophageal echocardiogram: a patent foramen ovale $\left(^{*}\right)$ is seen showing a protrusion of the upper area of the interatrial septum towards the left atrium (LA). In (B), (C), and (D) Doppler ultrasonography shows the abnormal direction of blood flow from the inferior vena cava (IVC) towards the interatrial septum resulting in a right-to-left shunt at this level. $R A=$ rigkt atrium; $A O=$ aorta.

pressure,$^{7}$ in pulmonary emboli, ${ }^{8}$ pulmonary hypertension, ${ }^{8}$ chronic obstructive pulmonary disease, ${ }^{9}$ orthodeoxia platypnoea often associated with pneumonectomy, ${ }^{2}$ pulmonary valve stenosis, congestive cardiac failure, and cardiac tumours. ${ }^{1}$

Right-to-left shunt occurs less frequently with normal right atrial pressures. ${ }^{12}$ Several hypotheses accounting for this uncommon phenomenon have been proposed ${ }^{1}$ : (1) transient peak rather than mean arterial pressure differentials during the normal cardiac cycle; (2) a flow phenomenon with venous blood from the inferior vena cava directed preferentially towards the foramen ovale; (3) a decrease in right ventricular compliance causing an increase in right arterial pressure; or (4) production or accentuation of interatrial gradients with respiration and the Valsalva manoeuvre.

In our patient the occurrence of unilateral diaphragm paralysis was a triggering mechanism which might have transiently modified the direction of the flow from the inferior vena cava towards the foramen ovale in the interatrial septum, causing a right-to-left shunt with normal pressures in the right atrium, ventricle, and in the pulmonary artery.

Although unilateral diaphragmatic paralysis can cause a small drop in $\mathrm{PaO}_{2}$ due to ventilation-perfusion inequality, ${ }^{10}$ a sudden impairment in oxygen tensions without any obvious radiological or clinical changes should make one suspect intracardiac shunting. ${ }^{7}$ If the patient is also immobile, treatment with anticoagulants should be started in order to avoid paradoxical embolism.

1 Strunk BL, Cheitlin MD, Stulbarg MS, Schiller NB. Rightto-left interatrial shunting through a patent foramen ovale despite normal intracardiac pressures. Am f Cardiol 1987 60:413-5.

2 Seward JB, Hayes DI, Smith HC, Williams DE, Rosenow EC, Reeder GS, et al. Platypnea-orthodeoxia: clinical profile, diagnostic workup, management, and report of profile, diagnostic workup, management, and
seven cases. Mayo Clin Proc 1984;59:221-31.

seven cases. Mayo Clin Proc 1984;59:221-31.
3 Hagen PT, Scholz DG, Edwards WD. Incidence and size of patent foramen ovale during the first 10 decades of life: an autopsy study of 965 normal hearts. Mayo Clin Pro 1984;59:17-20.

4 Meister SG, Grossman W, Dexter L, Dalen JE. Paradoxical embolism. Diagnosis during life. Am $\mathcal{F}$ Med 1972;53 292-8.

5 Prec KJ, Cassels DE. Oximeter studies in newborn infants during crying. Pediatrics 1952;9:756-62.

6 Kronik G, Mösslacher H. Positive contrast echocardiography in patients with patent foramen ovale and normal right heart hemodynamics. Am $\mathcal{F}$ Cardiol 1992;49: 1806-9.

7 Moorthy SS, Losasso AM. Patency of the foramen ovale in critically ill patient. Anesthesiology 1974;41:405-7.

8 Schroeckenstein RF, Wasenda GJ, Edwards JE. Valvular competent patent foramen ovale in adults. Minn Med competent paten

9 Daly JJ. Venoarterial shunting in obstructive pulmonary disease. N Engl F Med 1968;278:952-3.

10 Clague HW, Hall DR. Effect of posture on lung volume: airway closure and gas exchange in hemidiaphragmatic paralysis. Thorax 1979;34:523-6. 